\title{
El principio de objetividad en la contratación pública
}

\author{
Miguel Ángel Bernal Blay \\ Profesor Ayudante Doctor Universidad de Zaragoza \\ mabernal@unizar.com
}

\begin{abstract}
La contratación representa una parte importante de la actividad administrativa, y como tal se encuentra sometida a unos grandes principios, entre los que se encuentra el de objetividad, que en este ámbito de actuación presenta un alcance y significado particular. Se trata de un principio que resulta de aplicación a todos los contratos del sector público, al margen de su naturaleza administrativa o privada, y al margen también de su cuantía, de carácter trasversal, al manifestarse en todas las fases del procedimiento. En todas ellas quiere aludir a la relación de los elementos propios de cada fase con la prestación que constituye el objeto del contrato.
\end{abstract}

Palabras clave Contratación pública, principios generales, criterios de adjudicación, recurso especial en materia de contratación.

\section{The principle of objectivity in public procurement}

\begin{abstract}
Public procurement represents an important part of the administrative activity, so in them there are some principles applicable. The principie of objectivity is one of them, which in this policy area has an special meaning. It is a principle applicable to all public sector contracts, regardless of administrative or private nature, and also regardless of is amount, and plays in all phases of the procedure. In all of them wants to allude to the relationship of the elements of each phase with the subject of the contract.
\end{abstract}

\section{Key words}

Public procurement, general principles, award criteria, remedies in public procurement. 


\section{SIGNIFICADO Y ALCANCE DEL PRINCIPIO DE OBJETIVIDAD EN LA CONTRATACIÓN PÚBLICA}

La actividad contractual pública representa un importante porcentaje del PIB. Aun cuando es difícil que se haya mantenido en el actual contexto de desaceleración económica, un informe de la Comisión Europea de 2011 cifraba en un 18,5 \% del PIB el importe que respecto del PIB habían supuesto los contratos públicos en España en el año 2009'. Dicha cifra integra los contratos adjudicados por los poderes adjudicadores españoles, concepto de origen europeo que, en el plano nacional, integra tanto a las Administraciones públicas, en el sentido que este concepto tiene para la normativa sobre contratos públicos, como a un conjunto de entidades de carácter instrumental creadas para satisfacer necesidades de interés general².

Su regulación ha sido objeto de sucesivas modificaciones en los últimos tiempos, quizás demasiadas (diez en un plazo de poco más de tres años y medio) para una norma "estructurante" del ordenamiento jurídico3. Tal circunstancia hizo patente la necesidad de aprobar un Texto Refundido de la Ley de contratos del Sector Público (TRLCSP) que finalmente vio la luz el 14 de noviembre de 2011, al aprobarse el Decreto Legislativo 3/2011, de 14 de noviembre, que entró en vigor el 16 de diciembre de 2011.

Habida cuenta de la relevancia que desde el punto de vista económico representa la actividad contractual pública, su gestión no puede escapar a la aplicación de los principios que disciplinan la actuación administrativa. En particular, resulta de aplica-

1 Public Procurement Indicators 2010, de 4 de noviembre de 2011, accesible desde http://ec.europa. eu/internal_market/publicprocurement/docs/indicators2010_en.pdf

2 El ámbito de aplicación subjetivo de la normativa sobre contratos públicos ha sido abundantemente abordado por la doctrina científica, la jurisprudencia y los diversos órganos consultivos. Podemos destacar entre los trabajos doctrinales más recientes, el de Pleite Guadamillas, F.: El ámbito de aplicación subjetiva de la Ley de contratos del Sector público. Claves para la clasificación de los poderes adjudicadores, La Ley, 2010. Por cuanto respecta a la jurisprudencia, en su día el prof. García de Enterría abordó el análisis de dos Sentencias del Tribunal de Justicia de la Unión Europea que condenaron al Reino de España por una inadecuada transposición de la Directiva Europea en materia de ámbito subjetivo: “El Tribunal de Justicia de las Comunidades Europeas constata y censura dos graves quiebras de nuestro Derecho administrativo en materia de entes sujetos al Derecho Público y de medidas cautelares contencioso-administrativas. (Sentencia Comisión c. España de 15 de mayo de 2003, As. C-214/00), Revista Española de Derecho Administrativo n. ${ }^{\circ} 119$, págs. 471-487, y "Una nueva Sentencia del Tribunal de Justicia de las Comunidades Europeas sobre la sumisión a las normas comunitarias sobre contratación pública de las sociedades mercantiles de titularidad de las Administraciones Públicas", Revista Española de Derecho Administrativo n. ${ }^{120}$, págs. 667-677. Finalmente, por cuanto respecta a la función consultiva, también resulta recomendable leer la Circular 1/2008, de 3 de marzo, de la Junta Consultiva de Contratación Administrativa de la Comunidad Autónoma de Aragón, sobre "alcance del ámbito subjetivo de aplicación de la LCSP y régimen de contratación aplicable".

3 Diversos trabajos se han ocupado de sistematizar esas modificaciones. Por ejemplo, el de J. M. Gimeno Feliú Las reformas legales de la Ley 30/2007, de contratos del Sector público, Civitas, Colección Cátedra de Derecho Local, 2011, y el de J.A. Moreno Molina "Las últimas reformas en materia de contratos públicos y el futuro próximo: crónica de una avalancha normativa”, en Observatorio de los contratos públicos 2010, Civitas, 2011, págs. 105 a 124.. Con carácter complementario, puede verse también el trabajo de A.I. Beltrán Gómez "Medidas adoptadas por las Comunidades Autónomas en materia de contratos públicos, también en el Observatorio de los contratos públicos 2010, págs. 125 a 142. 
ción a la gestión de los contratos públicos la vinculación al servicio a los intereses generales (art. 103.1 C.E.), que en materia de contratación administrativa (contratos celebrados por entidades que, a efectos de I TRLCSP tienen la consideración de Administración pública, art. 3.2 TRLCSP) se manifiesta, entre otras, en la obligatoriedad de adjudicar los contratos a la oferta económicamente más ventajosa ${ }^{4}$ (Cfr. art. 150 TRLCSP), quedando sometida la modificación de sus términos a la justificación de la concurrencia de causas de interés público (Cfr. art. 219 TRLCSP). Pero además, en materia de contratación pública se han consolidado unos principios generales específicos, enunciados en la Directiva que promueve la coordinación de los procedimientos de adjudicación de contratos públicos de obras, servicios y suministros (Directiva 2004/18, de 30 de marzo, art. 2), perfilados por la jurisprudencia europea, e incorporados al TRLCSP (Cfr. arts. 1 y 139), cuyo fundamento no es otro que el de asegurar que las decisiones de compra pública se orientan a la satisfacción de esos intereses generales. Sólo de esta manera cobra sentido la contratación pública, entendida no como un fin en sí misma, sino como una herramienta para la consecución de los intereses generales 5 .

Así, pueden identificarse como principios generales de la contratación pública los de igualdad, no discriminación, transparencia, publicidad y concurrencia, a los que el TRLCSP ha añadido algunos "principios de conducta", al señalar la necesidad de que en la actividad contractual pública se asegure, en conexión con el objetivo de estabilidad presupuestaria y control del gasto, una eficiente utilización de los fondos destinados a la realización de obras, la adquisición de bienes y la contratación de servicios mediante la exigencia de la definición previa de las necesidades a satisfacer, la salvaguarda de la libre competencia y la ya mencionada, selección de la oferta económicamente más ventajosa.

Es cierto que el principio de objetividad no aparece expresamente incluido en esa relación de "principios generales" que se identifican en la normativa reguladora de la contratación pública. Sin embargo, sí que, como veremos, en determinados preceptos se alude a la objetividad, y por tanto, puede considerarse, al igual que los anteriores, otro principio general, con un significado propio y diferenciado del resto,

4 Sobre el concepto puede verse Gimeno Feliú, J.M.: “La adjudicación de los contratos: la oferta económicamente más ventajosa", en la obra colectiva por él mismo dirigida El derecho de los contratos públicos, Monografía núm. X de la Revista Aragonesa de Administración Pública, Zaragoza, 2008, págs. $155-184$.

5 Sobre esta consideración, Gimeno Feliú ya apuntó que la contratación pública no puede ser considerada como un fin en si mismo sino que debe ser visualizada como una potestad o herramienta jurídica al servicio Junta Consultiva de Contratación Administrativa de la Comunidad Autónoma de Aragón de los poderes públicos para el cumplimiento efectivo de sus fines o sus políticas públicas. Es decir, la contratación puede, y debe ser, una técnica que permitiera conseguir objetivos sociales, ambientales o de investigación, en la convicción de que los mismos comportan una adecuada comprensión de cómo deben canalizarse los fondos públicos. Esto significa que los contratos públicos no constituyen exclusivamente un medio de abastecerse de materias primas o de servicios en las condiciones más ventajosas para el Estado, sino que, en la actualidad, a través de la contratación pública, los poderes públicos realizan una política de intervención en la vida económica, social y política del país, Novedades de a Ley de contratos del sector público de 30 de octubre de 2007 en la regulación de la adjudicación de los contratos públicos, Civitas, 2010, pág. 20. 
aunque, evidentemente, relacionado ${ }^{6}$. En efecto, en los contratos públicos el principio de objetividad adquiere su sentido al identificar un vínculo, directo o indirecto, con el objeto de los mismos, abstrayendo las cuestiones que afectan a los elementos personales de la relación (contractual).

Tendremos ocasión de comprobar, al abordar a continuación el análisis de las diferentes manifestaciones de dicho principio en cada una de las fases del procedimiento de adjudicación, sobre qué elementos se proyecta esa vinculación con el objeto del contrato, y analizaremos en particular los mecanismos de selección de licitadores, de valoración de las ofertas, y de modificación de los contratos.

No obstante, sí que entendemos preciso realizar, siquiera brevemente, alguna apreciación sobre el alcance del principio de objetividad en la contratación pública. Debemos hacer referencia, en primer lugar, a su carácter transversal, del cual resulta su aplicación a todas las fases de un contrato público, desde la preparación y adjudicación, pasando por los efectos del mismo durante su ejecución y hasta su extinción mediante el cumplimiento por las partes de sus respectivas contraprestaciones. Ocasión tendremos más delante de comprobar cómo dicho principio se manifiesta en cada una de esas fases. En segundo lugar, y por cuanto respecta al alcance objetivo del principio, debemos señalar que dicho principio proyecta su influencia tanto sobre los contratos sujetos a las prescripciones de las Directivas europeas ("sujetos a regulación armonizada", si utilizamos la terminología del TRLCSP), como a aquéllos que, por razón de su cuantía, no superan los umbrales económicos de relevancia europea?. En este sentido, resulta relevante que la propia Comisión Europea, en su Comunicación interpretativa de 1 de agosto de 2006 sobre el Derecho comunitario aplicable en la adjudicación de contratos no cubiertos o sólo parcialmente cubiertos por las Directivas sobre contratación pública (2006/C 179/02), relacionara dicho principio entre los mecanismos para asegurar la imparcialidad de las adjudicaciones de esos contratos no cubiertos o únicamente cubiertos de forma parcial por las disposiciones de la Directiva. Por último, la determinación del alcance subjetivo del principio de objetividad en la contratación pública exige tomar en consideración el ámbito de aplicación subjetivo de la normativa sobre contratos públicos, recogido en el art. 3 TRLCSP. Según dicho precepto, las disposiciones del TRLCSP no resultan de aplicación únicamente a las entidades que se identifican como Administraciones públicas a los efectos del TRLCSP, sino también a entidades que no tienen tal consideración, como los poderes

6 De hecho no resulta infrecuente entre la doctrina que el tratamiento de los principios generales de la contratación pública incluya también al principio de objetividad. Así lo hace, por ejemplo, J.A. Moreno Molina, que se ha ocupado monográficamente del estudio de dichos principios (Los principios generales de la contratación pública, Bomarzo, 2006), quien destaca su prevalencia sobre cualquier otra función de la normativa sobre contratación, afirmando que dichos principios son en nuestros días el fundamento de todas las reglas públicas sobre contratos público, La nueva Ley de contratos del Sector público. Estudio sis-

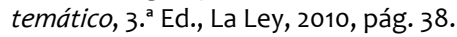

7 Víd. los nuevos umbrales establecidos por el Reglamento (CE) n. ${ }^{\circ}$ 1251/2011 de la Comisión de 30 de noviembre de 2011 por el que se modifican las Directivas 2004/17/CE, 2004/18/CE y 2009/81/CE del Parlamento Europeo y del Consejo en lo que concierne a sus umbrales de aplicación en materia de procedimien-

132 tos de adjudicación de contratos. 
adjudicadores, u otras entidades del sector público. Interesa destacar que esa distinción de entes sujetos a las disposiciones del TRLCSP supone la atribución de una naturaleza jurídica diversa a los contratos celebrados por cada una de esas entidades: naturaleza administrativa, cuando se trate de contratos celebrados por entidades que, a efectos del TRLCSP, tengan la consideración de Administración pública (art. 19 TRLCSP), y naturaleza privada, cuando quien celebre el contrato sea una entidad distinta (art. 20 TRLCSP). Y consecuentemente, de un régimen jurídico que presentará acusadas diferencias entre ambos tipos de contratos. Sin embargo, a efectos de aplicación del principio de objetividad resulta indiferente la naturaleza pública o privada del instrumento jurídico en el que se materialice el contrato, resultando de aplicación a todos los contratos públicos (del Sector público), al margen de su naturaleza (y régimen jurídico) administrativa o privada.

\section{CONTROL DE LA OBJETIVIDAD EN LA CONTRATACIÓN PÚBLICA: EL RECURSO ESPECIAL}

Antes de abordar las diversas manifestaciones del principio de objetividad en la contratación pública entendemos conveniente introducir las posibilidades de control de su cumplimiento. Nos referimos al recurso especial en materia de contratación pública, introducido por la Ley 30/2007, de 30 de octubre, de contratos del sector público, y que se ha mantenido en el TRLCSP, aun cuando sufrió una importante modificación a través de la Ley 34/2010, de 5 de agosto, que incorpora al Ordenamiento español las prescripciones de la Directiva 2007/66/CE, de 11 de diciembre ${ }^{8}$.

Esta última norma introduce algunas modificaciones con respecto a la regulación inicial del recurso especial en materia de contratación. Debemos destacar el carácter potestativo que ahora caracteriza el recurso, frente al preclusivo característico del recurso en su versión originaria. Como ya hemos señalado en otro lugar ${ }^{9}$, ese carácter potestativo del recurso especial en materia de contratación supone de facto la apertura de una doble vía de recurso (administrativo especial o jurisdiccional) para la

8 Sobre el contenido de la Ley 34/2010 puede verse recientemente, J.M. Gimeno Feliú: Las reformas legales de la Ley 30/2007, de contratos del sector público, Civitas, Colección Cuadernos de la Cátedra de Derecho Local de Aragón, 2011; J.A. Moreno Molina: La reforma de la Ley de contratos del Sector público en materia de recursos. Análisis de la ley 34/2010, de 5 de agosto, La Ley, Madrid, 2010; I. Gallego Córcoles: "Comentario a la Ley 34/2010, de 5 de agosto" en F. Castro Abella (Coord.) Contratación del Sector público

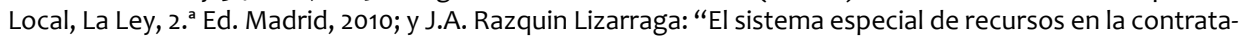
ción pública tras la reforma de la Ley de Contratos del Sector Público” Revista General de Derecho Administrativo núm. 25, 2010. Sobre la Directiva Vid. B. Noguera de la Muela, "El recurso especial en materia de contratación y las medidas cautelares en la Ley 30/2007, de 30 de octubre, de contratos del Sector Público, a la vista de la Directiva 2007/66/CE, por la que se modifica la Directiva 89/665/CEE", en J.M. Gimeno Feliú (Ed): El Derecho de los contratos públicos, Monografía núm. X de la Revista Aragonesa de Administración Pública, especialmente pp. 299-312.

9 "Nueva configuración del recurso especial en materia de contratación pública. Comentario al Proyecto de Ley por el que se adapta la Ley de contratos del Sector Público a la Directiva 2007/66/CE, de 11 de diciembre de 2007", en el núm. 100 de la Revista Contratación Administrativa Práctica, pp. 31-44 
impugnación de acuerdos tomados en el seno de un procedimiento de contratación. Tal circunstancia, parece que admisible desde el punto de vista europeo, no está exenta de dificultades prácticas, habida cuenta de las diferencias procesales existentes en el plano nacional en función de optar por la vía administrativa o la judicial. De esas diferencias procesales, la que con mayor claridad se advierte es el plazo para la interposición de los recursos, 15 días hábiles, computados de manera diferente en función del acto que se recurra (art. 44.2 TRLCSP), para el caso del recurso especial en materia de contratación pública, o bien dos meses contados desde el día siguiente al de la publicación de la disposición impugnada o al de la notificación o publicación del acto que ponga fin a la vía administrativa, si fuera expreso (art. 46.1 de la Ley 29/1998, de 13 de julio, reguladora de la Jurisdicción Contencioso-Administrativa), para el caso de interponer el recurso contencioso-administrativo.

La utilidad del recurso deriva de la atribución de la competencia para su conocimiento a un órgano independiente del que ha tomado la decisión que se impugna, y aquí reside la novedad principal introducida por la Ley 34/2010. Recordemos que la redacción original de la LCSP, aun cuando estableció el recurso especial en materia de contratación, no contemplaba la independencia del órgano competente para resolverlo, ya que se atribuía dicha competencia al mismo órgano de contratación que dictara el acto recurrido. Con ocasión de la Ley 34/2010, para el conocimiento del recurso especial en materia de contratación pública, en el ámbito de la Administración General del Estado fue creado el Tribunal Administrativo Central de Recursos Contractuales (art. 41.1 TRLCSP), órgano que, a pesar de que de su denominación pudiera deducirse lo contrario, tiene naturaleza administrativa y no judicial. Algunas Comunidades Autónomas han creado órganos similares al Tribunal Central ${ }^{10}$. En unos casos se trata de órganos de carácter colegiado (Madrid ${ }^{11}$ y Aragón ${ }^{12}$ ), y en otros, por el momento, de carácter unipersonal (País Vasco ${ }^{13}$, Cataluña ${ }^{14}$ y Andalucía ${ }^{15}$ ). Para aquellas Comunidades Autónomas que no han creado este órgano independiente juega la regla contenida en la Disposición transitoria séptima TRLCSP según la cual la competencia para la resolución de los recursos continuará encomendada a los mismos órganos que la tuvieran atribuida con anterioridad. Esto es, sobrevive "el espíritu” del artículo 37.4 LCSP en su redacción original para mantener la competencia del órgano de contratación para resolver el recurso (cuando se trate de contratos de una Administración Pública), o del titular del departamento, órgano, ente u organismo al que esté adscrita la enti-

10 Sobre las características de estos órganos me remito a mi artículo "Aspectos orgánicos del recurso especial en materia de contratación pública en las Comunidades Autónomas”, Cuadernos de Derecho Local núm. 26, 2011, págs. 7-26.

11 Artículo 3 de la Ley 9/2010, de 23 de diciembre, de Medidas Fiscales, Administrativas y Racionalización del Sector Público.

12 Artículo 17 de la Ley 3/2011, de 24 de febrero, de medidas en materia de Contratos del Sector Público de Aragón

13 Disposición Adicional Octava de la ley 5/2010, de 30 de diciembre, de Presupuestos generales de la Comunidad Autónoma de País Vasco para el ejercicio 2011

14 Disposición Adicional Cuarta de la Ley 7/2011, de 27 de julio, de medidas fiscales y financieras.

15 Decreto 332/2011, de 2 de noviembre, por el que se crea el Tribunal Administrativo de Recursos

134 Contractuales de la Junta de Andalucía. 
dad contratante o al que corresponda su tutela (si ésta no tiene el carácter de Administración Pública). Ahora bien, en tales supuestos, el procedimiento de tramitación de los recursos se acomodará a lo dispuesto en los artículos 312 a 318 LCSP, de los que deriva una suspensión automática de los actos de adjudicación, y además, cuando las resoluciones no sean totalmente estimatorias, o cuando siéndolo hubiesen comparecido en el procedimiento otros interesados distintos del recurrente, no serán ejecutivas hasta que sean firmes o, si hubiesen sido recurridas, hasta tanto el órgano jurisdiccional competente no decida acerca de la suspensión de las mismas. En el ámbito de las Corporaciones Locales, lo ordinario ha venido siendo que los órganos autonómicos creados asuman la competencia para resolver los recursos en materia de contratación interpuestos contra actos de las Corporaciones Locales que tengan su sede en su territorio. Ahora bien, esa regla general conoce de algunas excepciones. En el País Vasco, los municipios de más de 50.000 habitantes pueden crear su propio órgano competente para la resolución de los recursos de su ámbito local y sector público respecti$v^{16}$. Y lo mismo sucede con las entidades locales andaluzas, que además de poder crear sus propios órganos de recurso, pueden atribuir su conocimiento a órganos especializados en esta materia que puedan crear las Diputaciones Provinciales.

Algunas consideraciones merece el ámbito objetivo de actuación de estos órganos. En primer lugar, debemos tener en cuenta que no cualquier contrato es susceptible de recurso. El art. 40.1 TRLCSP somete la posibilidad de interponer el recurso especial a varias condiciones. La primera, que se trate de contratos licitados por un poder adjudicador, es decir, que no cabrá la interposición del recurso especial frente a contratos licitados por una entidad que tenga la consideración de Sector público a efectos del art. 3.1 TRLCSP, pero que no sea considerada poder adjudicador conforme al art. 3.3. Además, únicamente podrá interponerse recurso cuando se trate de contratos de obras, concesión de obras públicas, de suministro, de servicios, de colaboración entre el Sector Público y el Sector Privado y acuerdos marco, sujetos a regulación armonizada17; Contratos de servicios comprendidos en las categorías 17 a 27 del Anexo II TRLCSP cuyo valor estimado sea igual o superior a 200.000 euros, y contratos de gestión de servicios públicos en los que el presupuesto de gastos de primer establecimiento, excluido el importe del Impuesto sobre el Valor Añadido, sea superior a 500.000 euros y el plazo de duración superior a cinco años.

16 Igualmente cuentan con sus propios órganos de recurso las tres Diputaciones Forales. la provincia de Álava, mediante Decreto Foral 44/2010, de 28 de septiembre, aprobó la creación del Órgano Administrativo Foral de Recursos Contractuales; la de Guipúzcoa, mediante Decreto Foral 24/2010, de 28 de septiembre, la creación y regulación del Tribunal Administrativo Foral de Recursos Contractuales, y la de Vizcaya, mediante Decreto Foral 102/2010, de 29 de septiembre, la creación del Tribunal Administrativo foral de recursos contractuales

17 La existencia de este límite cuantitativo ha sido criticada en diversas ocasiones por la doctrina. Esas críticas han llevado a que alguna Comunidad Autónoma haya proyectado ampliar el ámbito objetivo del recurso (del cual conocerá su propio órgano independiente). Es el caso de Aragón, que en el Proyecto de Ley de medidas fiscales y administrativas de la Comunidad Autónoma de Aragón (Boletín Oficial de las Cortes de Aragón de 19 de diciembre de 2011) ha ampliado la competencia del Tribunal Administrativo de Contratos Públicos de Aragón para conocer de los recursos que se presenten respecto de los contratos de obras de importe superior a 1.000.000 € y de suministros y servicios superior a los $100.000 €$. 
En segundo lugar, debe advertirse que no cualquier acto de los que integran el procedimiento de contrataciónn es susceptible de ser recurrido. Según el art. 40.2 TRLCSP, lo serán los anuncios de licitación, los pliegos y los documentos contractuales que establezcan las condiciones que deban regir la contratación; los acuerdos de adjudicación adoptados por los poderes adjudicadores, y los actos de trámite adoptados en el procedimiento de adjudicación, siempre que éstos decidan directa o indirectamente sobre la adjudicación, determinen la imposibilidad de continuar el procedimiento o produzcan indefensión o perjuicio irreparable a derechos o intereses legítimos ${ }^{18}$. Sin embargo, no se consideran susceptibles de recurso especial en materia de contratación los actos de los órganos de contratación dictados en relación con las modificaciones contractuales no previstas en el pliego que, de conformidad con lo dispuesto en los artículos 105 a 107, sea preciso realizar una vez adjudicados los contratos tanto si acuerdan como si no la resolución y la celebración de nueva licitación ${ }^{19}$.

Hechas las anteriores consideraciones generales, en el apartado siguiente, al analizar las concretas manifestaciones del principio de objetividad, haremos referencia a algunas resoluciones de recursos especiales en materia de contratación que enjuician la objetividad de algunos elementos presentes en las diferentes fases que integran un procedimiento de contratación.

\section{MANIFESTACIONES DEL PRINCIPIO DE OBJETIVIDAD EN EL PROCEDIMIENTO DE ADJUDICACIÓN DE CONTRATOS DEL SECTOR PÚBLICO}

Enlazando con el carácter trasversal del principio de objetividad en la contratación pública al que antes hacíamos referencia, debemos señalar que todo procedimiento de adjudicación se desarrolla a través de diversas fases. Se inicia tras la preparación de un expediente, que aprueba el órgano competente para comprometer con

18 Se considerarán actos de trámite que determinan la imposibilidad de continuar el procedimiento los actos de la Mesa de Contratación por los que se acuerde la exclusión de licitadores.

19 Los términos en que se plantea la exclusión del recurso especial en materia de contratación plantean demasiados interrogantes. El ámbito objetivo de la exclusión se proyecta sobre "los actos de los órganos de contratación dictados en relación con las modificaciones contractuales no previstas en el pliego que, de conformidad con lo dispuesto en los artículos 105 a 107, sea preciso realizar una vez adjudicados los contratos tanto si acuerdan como si no la resolución y la celebración de nueva licitación.” ¿Significa eso que las modificaciones previstas en el pliego sí que pueden ser objeto de recurso? ¿Se excluye la posibilidad de interponer un recurso contra el acuerdo de modificación de un contrato no previsto en el pliego pero en el que se duda de la concurrencia de alguna de las causas del 107 TRLCSP? ¿Qué sentido tiene remitir al art. 106 TRLCSP (modificaciones previstas en la documentación que rige la licitación) como parámetro de corrección de las modificaciones no previstas en el pliego? Con la redacción dada al precepto parece más factible defender la posibilidad de interponer recurso contra los acuerdos de modificación de los contratos públicos que lo contrario. Gallego Córcoles participa igualmente de esta opinión crítica sobre la exclusión de los modificados del ámbito del recurso especial "Novedades en la regulación del recurso especial en materia de contratación: la discutible exclusión de las modificaciones contractuales ex lege de su ámbito

136 de aplicación", Contratación administas, núm. 113, 2011, págs. 32-37. 
su actuación a la Entidad contratante, al cual prosigue la presentación de proposiciones por los operadores económicos interesados. A la vista de las mismas, y aplicando los criterios que se hayan establecidos, se selecciona la oferta económicamente más ventajosa cuyo proponente será el encargado de ejecutar el objeto del contrato. Pues bien, en todas esas fases (preparación, adjudicación y ejecución) el principio de objetividad tiene alguna manifestación concreta, y su análisis es lo que ocupará nuestra atención en este apartado.

\subsection{El principio de objetividad en la selección de los licitadores}

Dentro de la fase de preparación de los contratos, uno de los trámites más importantes es aquél en el que se determinan las condiciones que necesariamente han de cumplir los interesados para acceder a la licitación. Podemos convenir en denominar a este trámite como de "selección de licitadores", para la cual se utilizan, fundamentalmente, dos instrumentos. Por un lado, la utilización de un determinado procedimiento de adjudicación, el procedimiento restringido, en el que únicamente pueden presentar ofertas los empresarios que previamente hayan sido seleccionados por el órganos de contratación (art. 162 TRLCSP). De otra parte, para acceder a un contrato público es necesario acreditar una determinada aptitud ${ }^{20}$. Tanto para la selección de licitadores en el procedimiento restringido, como para determinar la aptitud de los contratistas en el resto de procedimientos, se utiliza el instrumento de la solvencia económica y técnica exigible.

Interesa destacar que las condiciones mínimas de solvencia exigibles para ser admitido a la licitación, que operan como criterio de selección, son determinadas por los propios órganos de contratación (art. 62.1 TRLCSP). Pero la elección de los criterios de solvencia no es una facultad exenta de límites, antes al contrario, los criterios de solvencia que se decida utilizar deben ser objetivos, esto es, deben guardar relación con el objeto del contrato y ser adecuados a su dimensión (proporcionales) ${ }^{21}$.

20 Recordemos que el acceso a un contrato del sector público se encuentra condicionado subjetivamente a la acreditación de determinadas condiciones de aptitud. En este sentido, como recuerda el art. 54.1 TRLCSP, "sólo podrán contratar con el sector público las personas naturales o jurídicas, españolas o extranjeras, que tengan plena capacidad de obrar, no estén incursas en una prohibición de contratar, y acrediten su solvencia económica, financiera y técnica o profesional o, en los casos en que así lo exija esta Ley, se encuentren debidamente clasificadas".

21 El TRLCSP es especialmente exigente con la objetividad de los criterios de selección de los licitadores en el procedimiento restringido, señalando expresamente que "Con carácter previo al anuncio de la licitación, el órgano de contratación deberá haber establecido los criterios objetivos de solvencia, de entre los señalados en los artículos 75 a 79, con arreglo a los cuales serán elegidos los candidatos que serán invitados a presentar proposiciones" (art. 163.1 TRLCSP). Este especial énfasis aparece justificado por el hecho de que, en el procedimiento restringido, a diferencia de lo que sucede con el resto de procedimientos, la solvencia no es únicamente causa de admisión, sino también de selección. Es decir, que en el procedimiento restringido no participa toda aquél que cumple con los criterios de solvencia establecidos, sino únicamente aquéllos que, partiendo de que cumplen los requisitos de solvencia, son los más solventes de entre los solventes, y por eso son invitados por el órgano de contratación a presentar una oferta. Recuér- 
Así, como ha señalado Ruiz de Castañeda de la LLave, los criterios de solvencia deberán determinarse en función de las prescripciones técnicas, que expresan cómo se ejecutará el contrato, toda vez que de las mismas deberán deducirse los medios personales y materiales y la experiencia de que debe disponer el contratista ${ }^{22}$. En este sentido, el informe de necesidad de la contratación exigido en el artículo 22 TRLCSP, constituye el documento esencial para el control de la objetividad de los criterios de selección.

La fijación de los criterios de solvencia en el Pliego de cláusulas administrativas particulares permite el control de su objetividad utilizando el mecanismo del recurso especial en materia de contratación pública, al ser el Pliego un acto susceptible de impugnación (art. 40.2 TRLCSP), cuando el contrato sea uno de los que admiten la interposición de este recurso especial (art. 40.1 TRLCSP). Asi sucedió en el caso resuelto por el Tribunal de Contratos Públicos de Aragón mediante Acuerdo 2/2011, de 6 de abril ${ }^{23}$. Se trataba de un caso en el que se discutía la objetividad de algunos criterios de solvencia establecidos en el pliego de cláusulas administrativas particulares elaborado para la contratación del servicio de Asistencia Técnica al Consorcio "Candidatura Juegos Olímpicos Zaragoza-Pirineos 2022", que tenía por objeto la realización de estudios, análisis e informes técnicos necesarios relacionados con la candidatura, por procedimiento abierto. El Tribunal Administrativo aragonés reprocha en primer lugar la forma en que se ha determinado el propio objeto del contrato, que advierte expresamente de que, además de una serie de materias (que se explicitan a título meramente enunciativo) “... podrán comprender otros ámbitos técnicos que pudieran surgir, aun no estando explícitamente recogidos en los pliegos", circunstancia que no se acomoda a lo dispuesto en la normativa sobre contratación pública, que requiere que el informe de necesidad a que se refiere el art. 22 TRLCSP determine CON PRECISIÓN la naturaleza y extensión de las necesidades que pretenden cubrirse mediante el contrato proyectado, así como la idoneidad de su objeto y contenido para satisfacerlas.

Pero junto a ello, el Tribunal analiza la objetividad de algunas de las causas de solvencia exigidas por el Pliego, llegando a la conclusión, respecto de algunas de ellas, de la violación de dicho principio, al tratarse de criterios de solvencia que no guardan relación con el objeto del contrato. En particular, afirma el Tribunal Administrativo aragonés:

«... El medio de acreditación de solvencia, relativo a "haber realizado como mínimo un Plan de Ordenación o trabajo similar de ámbito territorial, valorándose especialmente aquellos cuyo ámbito de actuación sea un área de montaña" se considera

dese que el procedimiento restringido, el órgano de contratación puede decidir limitar el número de personas a las que se invitará a presentar proposiciones (art. 163.3 TRLCSP).

22 Voz "Solvencia de los contratistas", en Bermejo Vera, J. (Dir.) y Bernal Blay, M.A. (Coord.) Diccionario de contratación pública, lustel, Madrid, 2009, p. 630

23 Accesible desde http://w.aragon.es/estaticos/GobiernoAragon/OrganosConsultivos/JuntaConsultivaContratacionAdministrativa/Areas/Tribunal_admvo_contratos/Acuerdo_002_2011.pdf 
inadecuado por su indefinición y no se acredita su vinculación al objeto del contrato, ni la proporcionalidad del mismo. Máxime cuando la valoración no es posible en fase de acreditación de solvencia (al no utilizarse el procedimiento restringido ${ }^{24}$ ).

... En cuanto a "disponer de experiencia en la elaboración de estudios de desarrollo urbano en la ciudad de Zaragoza", no puede considerarse vinculado al objeto del contrato, pues el desarrollo urbano de Zaragoza es equivalente al de cualquier otra ciudad de su mismo tamaño y perfil...

... La necesidad de "acreditar experiencia en las relaciones con federaciones internacionales de deportes de invierno", justificada en que los responsables olímpicos y federativos serán interlocutores habituales durante la preparación de la candidatura y el momento de su venta, no resulta vinculada al objeto del contrato... como expresamente se declara en la cláusula 3 del Pliego de prescripciones técnicas, no es objeto de los trabajos la redacción de los documentos de candidatura, sino el apoyo mediante informes sectoriales que puedan servir para la elaboración de la documentación exigida en cada una de las fases, no correspondiendo a una oficina técnica de apoyo la interlocución con esos responsables. En todo caso, la exigencia es desproporcionada, ya que no se alcanza a comprender la especialidad de las federaciones internacionales de deportes de invierno frente a la de otras modalidades deportivas...»

Analizados los criterios de solvencia del pliego recurrido, de conformidad con los principios referidos, el Tribunal considera que el conjunto de los mismos es desproporcionado, y no guarda directa vinculación al objeto del contrato, y se introduce, de esta forma, un criterio discriminatorio, que tiene un efecto restrictivo de la competencia. En consecuencia, el Tribunal estima el recurso interpuesto contra el Pliego, declarando la invalidez de los criterios de solvencia, anulan los mismos y ordena su modificación.

El ejemplo anterior es uno de los muchos ejemplos con que podría ilustrarse el significado del principio de objetividad en la fase de selección de licitadores, y de las posibilidades de control que proporciona el ordenamiento jurídico.

\subsection{Los criterios objetivos de valoración de las ofertas}

Dentro de la fase de adjudicación de los contratos públicos, uno de los trámites esenciales que precede a los actos administrativos de adjudicación y formalización del contrato es la valoración de las ofertas presentadas por los licitadores admitidos. Esa valoración se realiza normalmente por un órgano auxiliar del órgano de contratación, la mesa de contratación, con arreglo a los criterios de adjudicación previamente fijados en el pliego de cláusulas administrativas particulares y que tienen por objeto determinar cuál es la oferta económicamente más ventajosa ${ }^{25}$.

24 La cursiva es nuestra.

25 Los criterios que han de servir de base para la adjudicación del contrato se detallarán en el anuncio, en los pliegos de cláusulas administrativas particulares o en el documento descriptivo (cuando el 
La determinación de los criterios de adjudicación en base a los cuales se determinará la oferta económicamente más ventajosa para la entidad contratante, y de su ponderación, es una facultad atribuida al órgano de contratación. Puesto que de los mismos depende muy estrechamente el resultado de la licitación, en el expediente de contratación deberá justificarse adecuadamente su elección (art.19.4 TRLCSP).

Tanto la normativa europea como española inciden en la necesidad de que los criterios de adjudicación que se utilicen sean objetivos. En su considerando núm. 46, la Directiva 2004/18 señala que la adjudicación del contrato debe efectuarse basándose en criterios objetivos que garanticen el respeto de los principios de transparencia, no discriminación e igualdad de trato ${ }^{26}$, así como la evaluación de las ofertas en condiciones de competencia efectiva, prescripción que se traduce posteriormente en el art. 53 de la misma (y que igualmente recoge el art. 150 TRLCSP) en la necesidad de que los criterios de adjudicación se encuentren vinculados al objeto del contrato. Sobre esta idea había incidido ya el Tribunal de Justicia en su Sentencia de 17 de septiembre de 2002 (C-513/99, Concordia Bus Finland), al señalar que como las ofertas se refieren necesariamente al objeto del contrato, los criterios de adjudicación que pueden aplicarse con arreglo a dicha disposición deben estar también relacionados con el objeto del contrato ${ }^{27}$. Esta exigencia de la vinculación directa con el objeto del contra-

procedimiento a utilizar sea el diálogo competitivo). Gimeno Feliú ha señalado que el incremento de la objetividad de los mismos pasaría por una publicación, lo más detallada posible de los criterios de adjudicación que van a utilizarse, del orden de preferencia de esos criterios y de las fórmulas o métodos que vayan a ser utilizados en la aplicación de cada uno de ellos y de su ponderación, y que tal medida contribuiría a promover la integridad de la contratación pública. “La Ley de contratos del sector público: ¿una herramienta eficaz para garantizar la integridad? Mecanismos de control de la corrupción en la contratación pública", Revista Española de Derecho Administrativo núm. 147, p. 528. Obviamente, aquellos criterios que no hayan sido señalados en el Pliego no podrán ser objeto de consideración (Informe JCCA del Estado núm. 36/04, de 7 de junio de 2004).

26 A fin de garantizar la observancia del principio de igualdad de trato en la adjudicación de los contratos, conviene establecer la obligación -consagrada por la jurisprudencia- de asegurar la transparencia necesaria para que cualquier licitador pueda informarse razonablemente de los criterios y modalidades que se aplicarán para determinar la oferta económicamente más ventajosa. Corresponde pues a los poderes adjudicadores indicar los criterios de adjudicación, así como la ponderación relativa atribuida a cada uno de dichos criterios, e indicarlo con antelación suficiente a fin de que los licitadores tengan conocimiento de ello para realizar sus ofertas. Los poderes adjudicadores podrán prescindir de indicar la ponderación de los criterios de adjudicación en casos debidamente justificados, que deben poder motivar, cuando esa ponderación no pueda establecerse previamente, debido, en particular, a la complejidad del contrato. En esos casos deben indicar los criterios por orden de importancia decreciente. A fin de garantizar la igualdad de trato, los criterios de adjudicación deben permitir comparar las ofertas y evaluarlas de manera objetiva. Si se reúnen estas condiciones, determinados criterios de adjudicación económicos y cualitativos, como los que se refieren al cumplimiento de las exigencias medioambientales, podrán permitir que el poder adjudicador satisfaga las necesidades del público afectado, tal como se definieron en las especificaciones del contrato. En estas mismas condiciones, el poder adjudicador podrá regirse por criterios destinados a satisfacer exigencias sociales que, en particular, respondan a necesidades-definidas en las especificaciones del contrato- propias de las categorías de población especialmente desfavorecidas a las que pertenezcan los beneficiarios/usuarios de las obras, suministros y servicios que son objeto del contrato.

27 Como acertadamente señala Ballesteros Moffa, por venir determinados en función de las características objetivas de cada contrato, los criterios no sólo operarán en orden a la selección de las ofertas, sino que decidirán también la previa inadmisión de aquellas que no cumplan con las especificaciones técnicas del pliego, La adjudicación de contratos en el sector público, Civitas, 2010, pág. 187. 
to, es decir la prestación, es decisiva a la hora de determinar qué criterios se pueden utilizar en la valoración de las ofertas. En efecto, como afirmaba la Junta Consultiva de Contratación Administrativa del Estado, en su Informe 9/o9, de 31 de marzo de 2009, la vinculación directa exige que el criterio de valoración afecte a aspectos intrínsecos de la propia prestación, a cuestiones relativas al procedimiento de ejecución o a las consecuencias directa derivadas de la misma. No puede afectar a cuestiones contingentes cuya alteración en nada altere ni la forma de ejecutar la prestación ni los resultados de la misma.

La determinación de esos criterios dependerá, por tanto, del objeto del contrato, de modo que los mismos deben permitir evaluar el nivel de rendimiento de cada oferta respecto del objeto del contrato, tal como se defina en las especificaciones técnicas, así como evaluar la relación calidad/precio de cada oferta. Y así, en el art. 150 TRLCSP se admiten como criterios de adjudicación objetivos, “la calidad, el precio, la fórmula utilizable para revisar las retribuciones ligadas a la utilización de la obra o a la prestación del servicio, el plazo de ejecución o entrega de la prestación, el coste de utilización, las características medioambientales o vinculadas con la satisfacción de exigencias sociales que respondan a necesidades, definidas en las especificaciones del contrato, propias de las categorías de población especialmente desfavorecidas a las que pertenezcan los usuarios o beneficiarios de las prestaciones a contratar, la rentabilidad, el valor técnico, las características estéticas o funcionales, la disponibilidad y coste de los repuestos, el mantenimiento, la asistencia técnica, el servicio postventa u otros semejantes".

El listado de criterios señalados en el art. 150 no agota todas las posibilidades existentes. Diversos órganos consultivos han analizado la posibilidad de utilizar otros criterios, concluyendo la viabilidad de su utilización como criterios de adjudicación al certificarse su naturaleza objetiva. Así, por ejemplo, se ha admitido la rentabilidad, entendida como un cociente entre beneficios, prestaciones o utilidad y costes (Informe JCCA del Estado 28/95, de 24 de octubre de 1995), el mayor número de elementos personales y materiales exigidos para determinar la solvencia técnica o profesional (Informe JCCA del Estado 59/04, de 12 de noviembre de 2004), la memoria constructiva, en un contrato de obras, cuando se aclare el modo en que se procederá a su valoración ${ }^{28}$ (Informe JCCA del Estado 30/07, de 5 de julio de 2007), y la calidad (incluida

28 Se entiende por memoria constructiva aquel documento contractual básico que, a la vista del proyecto de obras y su documentación, presenta el licitador en el marco de la proposición técnica. Este documento comprendería, entre otros: la explicación del resultado final que se concierta, la manifestación y justificación detallada por los candidatos a la adjudicación del contrato de la exposición de las unidades de obra previstas para ejecutar en el contrato, de los medios materiales adscritos para la realización de las unidades de obra, de las calidades a obtener en el proceso productivo durante la ejecución de los trabajos y el orden cronológico de realización de los mismos. La memoria constructiva debería contener las determinaciones a las que se refieren los artículos 132 y 144 del Reglamento General en relación con el programa de trabajo a presentar por el contratista una vez adjudicado el contrato y efectuada la comprobación de replanteo. Esto conllevaría un cierto grado de libertad en cuanto a sus determinaciones, proporcionando al órgano de contratación una información necesaria para poder conocer el desarrollo de la actividad que en cumplimiento de la prestación se propone realizar. 
en la lista de criterios del art. 150 TRLCSP), entendida como el posible control de calidad a efectuar en cuanto a los materiales y medios empleados en la ejecución del contrato $^{29}$ (Informe JCCA del Estado 53/97, de 2 de marzo de 1998). En cualquier caso, y relacionando estos dos últimos criterios, conviene señalar que la exigencia de una "memoria constructiva que detalle la programación de los trabajos, la organización y coordinación del proceso constructivo en el espacio y en el tiempo y la planificación y medios establecidos para el aseguramiento de la calidad" difícilmente pueden conceptuarse como criterio de calidad, sobre todo por su confusión con el programa de trabajo a que hacen referencia los artículos 124.1, letra e), de la Ley de Contratos de las Administraciones Públicas y 132 de su Reglamento (Informe JCCA del Estado 56/04, de 12 de noviembre de 2004).

Las anteriores consideraciones conducen a excluir la posibilidad de que puedan ser tenidos en consideración para la adjudicación del contrato criterios no vinculados con el objeto del contrato, sino con circunstancias personales de los licitadores. El caso paradigmático es el de la experiencia de los licitadores, incluida con frecuencia, hasta no hace mucho tiempo, como criterio de adjudicación. Al analizar este criterio, la jurisprudencia, tanto europea ${ }^{30}$ como nacional $^{31}$, ha sido bastante unánime al considerar que la experiencia es una condición de aptitud de los contratistas, que se rige por reglas distintas de las que se toman en consideración para la identificación de la oferta económicamente más ventajosa, y por ello ha rechazado la posibilidad de utilizar dicho criterio para la valoración de las ofertas.

Ahora bien, esta "consolidada" opinión puede ser objeto de matización en un futuro. En su Libro Verde sobre la modernización de la política de contratación pública de la UE: Hacia un mercado europeo de la contratación pública más eficiente, presentado el 27 de enero de 2011 (COM(2011) 15 final), la Comisión preguntaba (cuestión núm. 24) por la posibilidad de que en casos excepcionales, pudiera llegar a justificarse que los poderes adjudicadores tuvieran en cuenta criterios relativos al licitador como tal en la fase de adjudicación ${ }^{32}$. La respuesta de la Comisión a esta cuestión aparece

En cuanto a su contenido material y sus efectos como criterio de adjudicación, debe llamarse la atención sobre los aspectos subjetivos que el criterio concreto puede comportar si en el pliego no se determinan criterios claros que permitan llegar a una objetivización del mismo. Por tanto, la exigencia de aclarar como puntuar un criterio de adjudicación condiciona su posible aplicación.

29 La Junta Consultiva matiza que no puede pretenderse valorar la calidad como acreditación por certificados emitidos por personas o instituciones contratantes con anterioridad de los niveles de calidad obtenidos por las empresas en prestaciones semejantes a la del objeto del contrato, ya que con tal acepción el criterio sería equivalente al de experiencia, y por tanto, encubriría un requisito de solvencia (criterio que reitera la Junta Consultiva en su posterior Informe 50/06, de 11 de diciembre de 2006).

30 Víd. Sentencias del Tribunal de Justicia de 20 de septiembre de 1988 (As. C-31/87, Beentjes, apdos 15 y 16) y más recientemente la de 24 de enero de 2008 (As. C-532/06, Lianakis, apdos 26 a 28).

31 Víd. Sentencias del Tribunal Supremo de 21 de marzo de 2007, 24 de septiembre de 2008, o más recientemente, la de

32 La propia Comisión advierte que la aceptación de esa posibilidad introduciría un cambio fundamental en el sistema procedimental establecido en las Directivas de contratación pública. La separación entre criterios de selección y de adjudicación garantiza la equidad y la objetividad en la comparación de las ofertas. Permitir la inclusión de criterios relacionados con el licitador, como la experiencia y la cualificación, 
en su Propuesta de Directiva, donde explícitamente señala que, en los contratos de servicios y los contratos que impliquen la elaboración de proyectos de obras, "los poderes adjudicadores deben estar autorizados también a utilizar como criterio de adjudicación la organización, la cualificación y la experiencia del personal encargado de ejecutar el contrato, ya que pueden afectar a la calidad de dicha ejecución y, en consecuencia, al valor económico de la oferta" (Cfr. Considerando 41 y art. 66.2.b de la Propuesta de Directiva relativa a la contratación pública presentada el 20 de diciembre de 201133). Al menos se exige, como cautela, que tras la adjudicación del contrato, dicho personal solo se podrá sustituir con el consentimiento del poder adjudicador, que deberá comprobar que las sustituciones garantizan una organización y calidad equivalentes.

Otro ejemplo de criterios de adjudicación vetados, por no ser objetivos, son aquellos relacionados con la implantación de las empresas en un territorio, es decir, la atribución a las ofertas presentadas por empresas que tengan un determinado arraigo en el territorio de la entidad contratante (domicilio, delegación u otro cualquiera) de una bonificación en la valoración de sus ofertas por esta sola circunstancia (Informe JCCA del Estado 9/09, de 31 de marzo de 2009). Dos son los motivos fundamentales que justifican esta exclusión. Por una parte, que este tipo de criterios atenta contra el principio de no discriminación que recoge expresamente el TRLCSP en su art. 1 con carácter general, y posteriormente en el art. 139, específicamente para la adjudicación de los contratos, pero además, porque se trata de un criterio no vinculado con el objeto del contrato, pues las circunstancias referentes al origen o lugar en que la empresa realiza preferentemente sus actividades en nada influye ni en la prestación misma, ni en sus resultados, sino que se trata de un aspecto accidental. Por los mismos motivos queda excluida la posibilidad de tomar en consideración para la valoración de las proposiciones la colaboración, con anterioridad, con la entidad contratante, de las empresas licitadoras (Informe JCCA del Estado 13/06, de 24 de marzo)

Sin embargo, la diferenciación entre criterios vinculados al objeto del contrato y criterios subjetivos o aspectos accidentales no siempre está clara. Particular interés ha presentado la posibilidad de tomar en consideración para adjudicación de los contratos de criterios "sociales" 34 . En cuanto a los criterios de estabilidad de la plantilla

en tanto que criterios de adjudicación del contrato podría mermar la comparabilidad de los factores que deben tenerse en cuenta y, en última instancia, vulneraría el principio de igualdad de trato. Así pues, la dependencia de criterios relacionados con el licitador podría dar lugar también a falseamientos de la competencia. Por lo tanto, las propuestas que apuntan en esa dirección deben contemplarse, si acaso, tan solo en circunstancias limitadas, por ejemplo, para tipos específicos de contratos en los que las cualificaciones y el currículum del personal disponible sean especialmente importantes. En todo caso, cualquier cambio que tenga una repercusión en el principio de la separación de la selección y la adjudicación debe considerarse con extremo cuidado. Podría ser necesario introducir salvaguardias adicionales para garantizar la equidad y la objetividad de los procedimientos. PDF.

33 Accesible desde http://eur-lex.europa.eu/LexUriServ/LexUriServ.do?uri=COM:2011:0896:FIN:ES:

34 En otro lugar ya concluimos que la necesidad de su vinculación con el objeto del contrato hacía muy difícil la utilización de criterios sociales para la valoración de las ofertas. A nuestro juicio, la fase de 
de trabajadores de la empresa, de porcentaje de trabajadores con contrato indefinido y de las nuevas contrataciones de personal vinculadas a la ejecución del contrato es evidente que constituyen características de las empresas que no pueden funcionar como criterios de adjudicación en el concurso, sobre todo, dado que pueden producir un efecto discriminatorio respecto a los empresarios no españoles de Estados miembros de la Unión Europea cuyas respectivas legislaciones pueden no adecuarse con las categorías laborales de la legislación española o que se verán imposibilitados o en condiciones muy difíciles de cumplir, para acreditar que concurren los requisitos exigidos por los pliegos respectivos. (Informe JCCA del Estado 11/99, de 30 de junio de 1999). Lo mismo sucede respecto de los aspectos relativos a la prevención de riesgos laborales (Informe JCCA del Estado 42/06, de 30 de octubre de 2006). En cuanto al criterio de adjudicación de ejecución directa del contrato por trabajadores de la empresa su rechazo deriva de la propia regulación de la subcontratación en la normativa sobre contratos públicos, pues si esta última admite la subcontratación y establece sus requisitos, parece un contrasentido que, por vía de los criterios de adjudicación, se prime a las empresas que decidan no utilizar las posibilidades que la propia normativa les ofrece (Informe JCCA del Estado 36/01, de 9 de enero de 2002).

En conclusión, como señala Gimeno Feliú, los criterios de valoración de las ofertas deben necesariamente guardar relación con el qué, y nunca con el quién ${ }^{35}$.

No podemos terminar este apartado sin embargo sin señalar la estrecha relación que, en esta fase de valoración de ofertas, une a los principios de objetividad y de igualdad de trato a los licitadores. Como novedad, en la Ley 30/2007 se estableció un sistema de preponderancia de los criterios de valoración que puedan valorarse mediante cifras o porcentajes obtenidos a través de la mera aplicación de las fórmulas establecidas en los pliegos con respecto de aquellos respecto de aquellos cuya cuantificación dependa de un juicio de valor (art. 150.2 TRLCSP). Atención porque esta distinción parte del presupuesto de que ambas clases de criterios son objetivos, esto es, guardan relación con el objeto del contrato, con independencia de que su valoración dependa, bien de la aplicación de una fórmula, bien de un juicio de valor. Es decir, no pueden equipararse los conceptos criterios objetivos - criterios cuya valoración depende de la aplicación de una fórmula ya que igualmente son objetivos otros criterios cuya valoración depende de un juicio de valor. Es importante destacar este matiz porque en alguna ocasión la redacción del TRLCSP puede dar a entender lo contrario, por ejemplo, en el art. 152, cuando remite al Reglamento para determinar el carácter desproporcionado o anormal de las ofertas, en el supuesto en que el úni-

ejecución del contrato (mediante su configuración como condiciones especiales de ejecución) resulta mucho más idónea para tomar en consideración estos aspectos sociales. "Hacia una contratación pública socialmente responsable: las oportunidades de la Ley 30/2007, de 30 de Octubre, de Contratos del sector Público", en Monografías de la Revista Aragonesa de Administración Pública, Monográfico X, Zaragoza, 2008, págs 211 a 252.

35 "La adjudicación de los contratos: la oferta económicamente más ventajosa", en la obra colectiva por él mismo dirigida El derecho de los contratos públicos, Monografía núm. X de la Revista Aragonesa de Administración Pública, Zaragoza, 2008, pág. 161. 
co criterio valorable de forma objetiva a considerar para la adjudicación del contrato sea el de su precio.

Esta preferencia a favor de los criterios objetivos cuya valoración pueda obtenerse a partir de la aplicación de fórmulas o porcentajes llega hasta el punto de que cuando en una licitación que se siga por un procedimiento abierto o restringido se atribuya a los criterios evaluables de forma automática por aplicación de fórmulas una ponderación inferior a la correspondiente a los criterios cuya cuantificación dependa de un juicio de valor, debe constituirse un comité que cuente con un mínimo de tres miembros, formado por expertos no integrados en el órgano proponente del contrato y con cualificación apropiada ${ }^{36}$, al que corresponderá realizar la evaluación de las ofertas conforme a estos últimos criterios, o encomendar esta evaluación a un organismo técnico especializado, debidamente identificado en los pliegos. La finalidad de este Comité de expertos (figura creada en la LCSP, que recordemos no está exigida por las directivas comunitarias), no es otra que la de reforzar la objetividad en la valoración de ofertas, de manera que en los casos en que esta dependa mayoritariamente de juicios de valor y no de la mera aplicación de fórmulas matemáticas, la valoración de los mismos recaerá no en la mesa de contratación sino en un grupo de personas expertas. Esta es la diferencia fundamental respecto de los miembros de la mesa de contratación que no tienen por que ser expertos en la materia sobre la que versa la valoración.

Para extremar más la objetividad, los expertos en ningún caso podrán estar integrados en el órgano proponente del contrato. Sobre este concepto (órgano proponente del contrato), tanto la Junta Consultiva de Contratación Administrativa del Estado como la de la Comunidad Autónoma de Aragón, han coincidido en señalar que se trata de aquel órgano que en función de sus competencias, y según la singular estructura organizativa de los diferentes órganos de contratación, ejerce la iniciativa de la contratación proponiendo la celebración del contrato al órgano de contratación (Informe de la Junta Consultiva de Contratación Administrativa del Estado 34/09, de 25 de septiembre de 2009). Es decir, el órgano que según el artículo 73 del Reglamento de la Ley de Contratos de las Administraciones Públicas, que hay que considerar vigente en cuanto que no se opone al TRLCSP ni ha sido derogado por el Real Decreto $817 / 2009$, ha promovido el contrato y para ello ha emitido un informe razonado, exponiendo la necesidad, características e importe calculado de las prestaciones objeto del mismo (Informe 21/2009, de 16 de septiembre, de la Junta Consultiva de Contratación Administrativa de la Comunidad Autónoma de Aragón). En ningún caso podría

36 Sobre los conceptos de órgano proponente de la celebración del contrato y la composición del comité de expertos puede verse el Informe de la Junta Consultiva de Contratación Administrativa del Estado 34/09, de 25 de septiembre de 2009: Por órgano proponente de la celebración del contrato debe entenderse, según la singular estructura organizativa de los diferentes órganos de contratación, aquel que en función de sus competencias ejerce la iniciativa de la contratación proponiendo la celebración del contrato al órgano de contratación. Dispuesta la independencia de los miembros del comité de expertos encargado de la valoración de los criterios cuya cuantificación dependa de un juicio de valor sus miembros no pueden pertenecer a la Mesa de contratación. 
integrarse en el comité de expertos personas que formaran parte de la Mesa de contratación, aun expertas, pues en ese caso se quebraría la independencia exigida a dicho comité. Con esta prohibición tajante de que se designe para el comité de expertos a personal integrado en el órgano proponente del contrato se impide que aquel que haya podido participar directa o indirectamente en la configuración del contrato participe en la valoración de las ofertas que no sea meramente automática.

No obstante lo anterior, debe señalarse que el comité de expertos y su participación en el procedimiento de adjudicación presenta una complejidad que en muchos casos puede resultar una carga excesiva para contratos sencillos o para entidades pequeñas que no disponen de una organización administrativa importante. Ahora bien, recordemos que la utilización de un procedimiento en el que deba constituirse un comité de expertos es una opción del órgano de contratación, que puede buscar un procedimiento más sencillo simplemente evitando que los criterios de valoración no automáticos sean preponderantes en la adjudicación del contrato.

\subsection{La objetividad en la apreciación de las causas de modificación de los contratos públicos}

Finalmente, para concluir, resta por analizar de qué modo se manifiesta el principio de objetividad una vez perfeccionado el contrato, durante su ejecución, cuando diversos factores pueden hacer conveniente la necesidad de su modificación. Es aquí donde quizá pueda encontrarse una acepción distinta del concepto de objetividad que manejábamos al hablar de este principio en las fases de preparación y adjudicación de los contratos públicos.

El régimen jurídico de la modificación de los contratos públicos experimentó una profunda renovación con ocasión de la modificación de la LCSP por la Ley 2/2011, de Economía Sostenible. Dicha norma introdujo un nuevo Título (V) dentro del Libro I que ahora se encuentra integrado por los arts. 105 a 108 TRLCSP. Dichos preceptos regulan, en esencia, un sistema de modificación de los contratos que se asienta sobre unas causas previstas, bien en el propio contrato (art. 106), bien en la Ley (art. 107) y que debe ceñirse a introducir las variaciones estrictamente indispensables para responder a la causa objetiva que haga necesaria la modificación (art. 107.2 TRLCSP). Con independencia de las consecuencias de ubicar sistemáticamente la regulación de la modificación de los contratos públicos en el Libro I del TRLCSP, y no en el Libro IV, dedicado a la ejecución de los contratos, que ya pusimos de manifiesto en otro lugar37, sí que interesa llamar la atención sobre los presupuestos de aplicación de las causas de modificación de los contratos públicos.

37 Esta opción sistemática no resulta indiferente, pues sólo ese cambio de ubicación de la regulación tiene consecuencias en el ámbito práctico. La principal diferencia que se observa con respecto a la regulación anterior es que las nuevas reglas sobre modificación de los contratos no se vinculan al ejercicio de una prerrogativa por parte de una Administración pública en el seno de un contrato administrativo, sino 
En relación con las modificaciones previstas en la documentación que rige la licitación, el art. 106 TRLCSP dispone la necesidad de que "en los pliegos o en el anuncio de licitación se haya advertido expresamente de esta posibilidad y se hayan detallado de forma clara, precisa e inequívoca las condiciones en que podrá hacerse uso de la misma, así como el alcance y límites de las modificaciones que pueden acordarse, con expresa indicación del porcentaje del precio del contrato al que como máximo puedan afectar ${ }^{38}$, y el procedimiento que haya de seguirse para ello". Lo que en definitiva se pretende en este caso es convertir la potestad de modificación de los contratos en una potestad reglada, por ello se advierte en el mismo precepto que "los supuestos en que podrá modificarse el contrato deberán definirse con total concreción por referencia a circunstancias cuya concurrencia pueda verificarse de forma objetiva y las condiciones de la eventual modificación deberán precisarse con un detalle suficiente para permitir a los licitadores su valoración a efectos de formular u oferta y ser tomadas en cuenta en lo que se refiere a la exigencia de condiciones de aptitud a los licitadores y valoración de las ofertas". Interesante esta referencia que el precepto contiene a la necesidad de que la concurrencia de causas que justifican la modificación del contrato pueda verificarse de forma objetiva, esto es, sin que pueda remitirse la apreciación de su concurrencia o no a opiniones o dictámenes subjetivos (aun expertos). Como acertadamente ha señalado Colás Tenas, este requisito es una llamada al rigor en el estudio y la realización de los proyectos técnicos que son objeto de licitación, en el contrato de obras, y de los pliegos de prescripciones técnicas en el contrato de servicios. Detallar de forma clara, precisa e inequívoca las condiciones en que puede modificarse un contrato, así como el alcance y límites de las mismas, requiere método, estudio de las necesidades que debe satisfacer el proyecto y su asimilación, conocimiento, investigación de todos los factores que influyen en el resultado que se pretende, examen critico y sistemático de los modos de ejecución del contrato con el fin de advertir sus variables, trabajo, y, sobre todo, tiempo. El problema, señala este autor, es que cuando hay que hacer proyectos como churros, no es de extrañar que salga un churro de proyecto ${ }^{39}$.

que se proyectan sobre todos los contratos del sector público (administrativos o privados). Efectivamente, en atención a su ubicación sistemática en el Libro IV, las disposiciones sobre modificación de los contratos no resultaban aplicables a los contratos del sector público de naturaleza no administrativa sino privada, cuyo régimen de efectos, cumplimiento y extinción estaba sujeto no a la LCSP sino al Derecho privado, ex. art. 20.2 LCSP. De la nueva sistemática que utiliza el TRLCSP resulta que la regulación del régimen de modificación de los contratos ahora contenida en el Título V del Libro I TRLCSP es de aplicación a todos los contratos celebrados por entidades sujetas al TRLCSP, y no sólo a las Administraciones públicas, como sucedía con la regulación anterior, "Reflexiones sobre el régimen de ejecución de los contratos públicos", en Gimeno Feliú J.M. (Dir.) y Bernal Blay, M.A. (Coord.): Observatorio de los contratos públicos 2010, Civitas, 2011, pág. 177.

38 De manera consecuente, el importe que puedan llegar a alcanzar las modificaciones previstas habrá de tomarse en consideración para el cálculo del valor estimado del contrato, que puede condicionar el procedimiento de adjudicación, el régimen de publicidad del contrato y el sistema de recursos aplicable (Cfr. art. 88.1 pfo. 3 TRLCSP)

39 "La reforma de la legislación de contratos del sector público en la Ley de Economía sostenible: el régimen de modificación de los contratos del sector público", Tribuna El Derecho, accesible desde http:// www.elderecho.com/administrativo/legislacion-contratos-economia-sostenible-modificacion_11_ 281680002.html 
Continuando en el ámbito de las causas modificación de los contratos, el art. 107 TRLCSP se refiere a las causas no previstas en la documentación que rige la licitación. Aunque el precepto señala un heterogéneo grupo de causas, interesa llamar la atención sobre el supuesto contemplado en su apartado 1.b, relativo a la "inadecuación del proyecto o de las especificaciones de la prestación por causas objetivas que determinen su falta de idoneidad". Lo interesante de este supuesto es que es en el propio precepto donde se relacionan, de forma tasada cuáles son esas "causas objetivas" que determina la inidoneidad del proyecto o las especificaciones técnicas. Así, el precepto se refiere a circunstancias de tipo geológico, hídrico, arqueológico, medioambiental o similares, puestas de manifiesto con posterioridad a la adjudicación del contrato y que no fuesen previsibles con anterioridad aplicando toda la diligencia requerida de acuerdo con una buena práctica profesional en la elaboración del proyecto o en la redacción de las especificaciones técnicas ${ }^{40}$.

En consecuencia, parece que en esta fase de ejecución de los contratos públicos, parece que el principio de objetividad no se materializa tanto en una vinculación con el objeto del contrato cuanto en su relación con el principio de igualdad de los licitadores, impidiendo que una vez formalizado, el contrato pueda ser modificado por circunstancias que, de haber sido conocidas en el momento de realizar la oferta, pudieran haber supuesto la alteración de las efectivamente planteadas, de modo que se favorezca al adjudicatario en perjuicio del resto de licitadores.

\section{CONCLUSIONES}

El principio de objetividad, aunque no ha sido expresamente recogido en la normativa europea y española entre los principios generales de la contratación pública, ha sido elevado a tal consideración tanto por la doctrina, como por la jurisprudencia y por los órganos consultivos especializados en la materia.

Se trata de un principio aplicable a todos los contratos públicos, al margen de su naturaleza administrativa o privada, y al margen también de su importe económico, y que se manifiesta transversalmente en la selección de los licitadores, en la valoración de las ofertas, y posteriormente durante su ejecución. En todas esas fases dicho principio quiere poner de manifiesto la relación de algún elemento (los criterios de solvencia, los de adjudicación, o las causas de modificación) con el objeto del contrato, es decir, con la prestación o prestaciones que han sido identificadas como las idóneas para cubrir una necesidad de la entidad contratante, o con algún otro principio general de la contratación pública, especialmente el de igualdad de trato. Ese objeto del

40 Aunque no se diga expresamente, parece que se pretende dar un tratamiento diferente en función de si el contratista fue o no el autor del proyecto o intervino en la redacción de las especificaciones técnicas. Si no lo fue, cualquier error u omisión, que no le sería en ningún caso imputable, justifica la modificación contractual no prevista en los documentos de licitación. Si lo fue, para que el error u omisión haga posible dicha modificación, es preciso que no fuera previsible con la diligencia de un buen profesional. 
contrato es en realidad un presupuesto del mismo, de tal importancia que en materia de contratos públicos el legislador ha querido darle protagonismo evocando su presencia en todas las fases del procedimiento. De ahí que el objeto del contrato sea el elemento relacional que debe tomarse en cuenta para valorar la objetividad de los elementos protagonistas en cada una de esas fases del procedimiento: los criterios de solvencia, los de adjudicación, o las causas de modificación. Ayuda al control de esa objetividad en la contratación pública la posibilidad de utilizar el mecanismo de control ad hoc previsto en el TRLCSP, el recurso especial en materia de contratación pública, si bien entendemos que todavía puede mejorare dicho instrumento, ampliando su ámbito de actuación, lo que permitiría aumentar ese control de la objetividad en los contratos públicos.

\section{BIBLIOGRAFÍA}

Ballesteros Moffa, L.A.: La adjudicación de contratos en el sector público, Civitas, 2010. Beltrán Gómez, A.I.: “Medidas adoptadas por las Comunidades Autónomas en materia de contratos públicos, en Gimeno Feliú J.M. (Dir.) y Bernal Blay, M.A. (Coord.): Observatorio de los contratos públicos 2010, Civitas, 2011, págs. 125 a 142.

Bernal Blay, M.A.: "Reflexiones sobre el régimen de ejecución de los contratos públicos”, en Gimeno Feliú J.M. (Dir.) y Bernal Blay, M.A. (Coord.): Observatorio de los contratos públicos 2010, Civitas, 2011, págs. 143-210.

- “Aspectos orgánicos del recurso especial en materia de contratación pública", Cuadernos de Derecho Local núm. 26, 2011, págs. 7-26.

- "Nueva configuración del recurso especial en materia de contratación pública. Comentario al Proyecto de Ley por el que se adapta la Ley de Contratos del Sector Público a la Directiva 2007/66/CE, de 11 de diciembre de 2007”, en Contratación administrativa práctica: revista de la contratación administrativa y de los contratistas, núm. 100, 2010.

- "Hacia una contratación pública socialmente responsable: las oportunidades de la Ley 30/2007, de 30 de Octubre, de Contratos del sector Público", en J.M. Gimeno Feliú (Ed): El Derecho de los contratos públicos, Monografía núm. X de la Revista Aragonesa de Administración Pública,, págs 211 a 252.

Colás Tenas, J.: “La reforma de la legislación de contratos del sector público en la Ley de Economía sostenible: el régimen de modificación de los contratos del sector público", Tribuna El Derecho, accesible desde http://www.elderecho.com/administrativo/legislacion-contratos-economia-sostenible-modificacion_11_281680002.html

Gimeno Feliú, J.M.: Las reformas legales de la Ley 30/2007, de contratos del Sector público, Civitas, Colección Cátedra de Derecho Local, 2011

- "La Ley de contratos del sector público: ¿una herramienta eficaz para garantizar la integridad? Mecanismos de control de la corrupción en la contratación pública”, Revista Española de Derecho Administrativo núm. 147, págs. 517-536.

- Novedades de a Ley de contratos del sector público de 30 de octubre de 2007 en la regulación de la adjudicación de los contratos públicos, Civitas, 2010. 
- “La adjudicación de los contratos: la oferta económicamente más ventajosa”, en la obra colectiva por él mismo dirigida El derecho de los contratos públicos, Monografía núm. X de la Revista Aragonesa de Administración Pública, Zaragoza, 2008, págs. 155-184.

Gallego Córcoles, I: “Novedades en la regulación del recurso especial en materia de contratación: la discutible exclusión de las modificaciones contractuales ex lege de su ámbito de aplicación", Contratación administrativa práctica: revista de la contratación administrativa y de los contratistas, núm. 113, 2011, págs. 32-37.

García de Enterría, E.: “El Tribunal de Justicia de las Comunidades Europeas constata y censura dos graves quiebras de nuestro Derecho administrativo en materia de entes sujetos al Derecho Público y de medidas cautelares contencioso-administrativas. (Sentencia Comisión c. España de 15 de mayo de 2003, As. C-214/00), Revista Española de Derecho Administrativo n. ${ }^{\circ} 119$, págs. 471-487,

- "Una nueva Sentencia del Tribunal de Justicia de las Comunidades Europeas sobre la sumisión a las normas comunitarias sobre contratación pública de las sociedades mercantiles de titularidad de las Administraciones Públicas", Revista Española de Derecho Administrativo n. ${ }^{\circ} 120$, págs. 667-677. Diversos trabajos se han ocupado de sistematizar esas modificaciones.

Moreno Molina, J.A.: La nueva Ley de contratos del Sector público. Estudio sistemático,

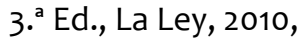

- "Las últimas reformas en materia de contratos públicos y el futuro próximo: crónica de una avalancha normativa", en Gimeno Feliú J.M. (Dir.) y Bernal Blay, M.A. (Coord.): Observatorio de los contratos públicos 2010, Civitas, 2011, págs. págs. 105 a 124 .

- La reforma de la Ley de contratos del Sector público en materia de recursos. Análisis de la ley 34/2010, de 5 de agosto, La Ley, Madrid, 2010

- Los principios generales de la contratación pública, Bomarzo, 2006

Noguera de la Muela, B.: "El recurso especial en materia de contratación y las medidas cautelares en la Ley 30/2007, de 30 de octubre, de contratos del Sector Público, a la vista de la Directiva 2007/66/CE, por la que se modifica la Directiva 89/665/CEE", en J.M. Gimeno Feliú (Ed): El Derecho de los contratos públicos, Monografía núm. X de la Revista Aragonesa de Administración Pública, especialmente pp. 299-312.

Pleite Guadamillas, F.: El ámbito de aplicación subjetiva de la Ley de contratos del Sector público. Claves para la clasificación de los poderes adjudicadores, La Ley, 2010.

Razquin Lizarraga, J.A.: "El sistema especial de recursos en la contratación pública tras la reforma de la Ley de Contratos del Sector Público" Revista General de Derecho Administrativo núm. 25, 2010.

Ruiz de Castañeda de la Llave, A.: Voz "Solvencia de los contratistas", en Bermejo Vera, J. (Dir.) y Bernal Blay, M.A. (Coord.) Diccionario de contratación pública, lustel, Madrid, 2009. 